\title{
Limonene oxidation over Ti-MCM-41 and Ti-MWW catalysts with t-butyl hydroperoxide as the oxidant
}

\author{
Alicja Gawarecka ${ }^{1} \cdot$ Agnieszka Wróblewska $^{1}$
}

Received: 20 December 2017/ Accepted: 18 March 2018/Published online: 21 March 2018

(C) The Author(s) 2018

\begin{abstract}
This paper presents the method of limonene epoxidation over Ti-MCM41 and Ti-MWW catalysts in the presence of t-butyl hydroperoxide as an oxidant. Natural limonene used in the epoxidation process was obtained via steam distillation (97\% purity). The purpose of the research was to obtain the highest yield of 1,2epoxylimonene, but the performed studies showed that the process of limonene epoxidation is more complex because in addition to epoxidation products $(1,2-$ epoxylimonene and its diol which were formed usually in small amount) also the following oxygenated derivatives of limonene are formed: carvone, carveol, and perillyl alcohol (products of allylic oxidation (hydroxylation) at positions 6 and 7 in limonene molecule). Therefore, ultimately, the most favorable conditions for the limonene oxidation process were selected at the highest conversion of limonene and at high values of perillyl alcohol and carveol or one of these two products. Perillyl alcohol and carveol have found numerous applications in medicine, among others, therefore this direction seems to be the most beneficial. This also work presents the short characteristization of the titanium silicate Ti-MCM-41 and Ti-MWW catalysts used in the research, taking into account their structure, properties and applications are presented.
\end{abstract}

Keywords Ti-MCM-41 · Ti-MWW · Limonene epoxidation · t-Butyl hydroperoxide

Agnieszka Wróblewska

agnieszka.wroblewska@zut.edu.pl

1 Faculty of Chemical Technology and Engineering, Institute of Organic Chemical Technology, West Pomeranian University of Technology Szczecin, Pułaskiego 10, 70-322 Szczecin, Poland 


\section{Introduction}

Crystalline aluminosilicates from the IA and IIA group are called zeolites. Zeolites in aluminosilicate forms for a long time have been used as a solid-acid catalyst in petrochemical industry. An example is Faujasite, which is wildly used as a catalyst in catalytic cracking process. It replaced commonly used amorphous silica-alumina catalysts [1-3].

The Ti-MWW material is one of the latest titanium-silicate catalysts. It was prepared by the method of hydrothermal synthesis using hexamethyleneimine as the structure-directing agent (template). The relevant structural parameter of zeolite structures is the size of pores. Ti-MWW catalyst have two-dimensional sinusoidal channels with 10-membered rings running through the structure and also it has the independent channel system includes large supercages. Taking into account the specific structure of Ti-MWW material it can find many applications in catalysis [4]. The catalytic properties of Ti-MWW catalyst were checked by Kim et al. [5] in 1-hexene epoxidation, in the oxidative desulfurization (ODS) of model sulfur compounds, in the direct conversion of methanol and in allyl chloride (ALC) epoxidation. Researchers observed high efficiency in each of these processes.

After discovering the mesoporous material of M41S type in 1992 [6], many scientists were engaged in the synthesis metallosilicates Me-MCM-41 (Mevarious transition metals) and applying them in liquid-phase oxidation processes. Ti-MCM-41 belongs to the family of mesoporous molecular sieves which is named M41S [7]. MCM-41 has a hexagonal array of unidirectional tubular pores [8]. The mosopores are distributed in straight one-dimensional channels with the same diameter and this structure resemble a honeycomb. The average pore size in this material is $4.9 \mathrm{~nm} \times 7.6 \mathrm{~nm}$, surface area amounts to $1200 \mathrm{~m}^{2} / \mathrm{g}$ and thickness of pore walls is within the range of $0.8-1.2 \mathrm{~nm}$ [9]. First report describing the TiMCM-41 catalyst was published in 1994 [10, 11]. Ti containing MCM-41 can find potential applications in epoxidation of olefins [11] and plants oils [12], and also in oxidation of sulfides [13] or unsaturated alcohols [14].

Limonene is cyclic monoterpene which has a center of asymmetry on the 4th carbon atom and therefore may exist as a two enantiomers: $\mathrm{R}(+)$ and $\mathrm{S}(-)$ and also as a racemic mixture-dipentene. Limonene is a colorless oil with a pleasant citrus aroma, which is insoluble in water $\left(0.15 \mathrm{mmol} / \mathrm{dm}^{3}\right.$ at $\left.25^{\circ} \mathrm{C}\right)$ but soluble in most organic solvents. It has a boiling point in the range of temperatures $176-177^{\circ} \mathrm{C}$. Limonene is a fragrant compound, but its enantiomers have different odors. R-(+)Limonene has the citrus scent and it is a component of many essential oils for example: orange, lemon, caraway and grapefruit. S-(-)-Limonene occurs in the oil of pine and fir, and has a characteristic smell of coniferous trees and shrubs. Racemic limonene was found in the bergamot essential oil and in camphor. R-(+)Limonene on industrial scale is produced from waste orange peels from juices industry. Main methods for obtaining of limonene are the steam and simple distillation, cold pressing or solvent extraction. The other methods of limonene obtaining is dimerization of isoprene [15], thermal isomerization of $\alpha$-pinene and camphene [16], and pyrolysis of natural rubber. Another method of the production 
of the limonene is vacuum pyrolysis of used tires. Polyisoprene or natural rubber composes approximately $50-60 \%$ of a typical truck tire formulation. They are an ideal source for the production of $\mathrm{R}(+)$-limonene [17].

Limonene has a lot applications in various branches of industry. It is used in: cosmetic, perfume and food industries. In industry, it is used as an environmentally friendly solvent for paints, varnishes and resins. Furthermore, limonene has antibacterial and antifungal properties and it is applied in agriculture and veterinary medicine as a natural repellent [18]. The oxygenated derivatives of limonene also find many valuable applications in the industry, for example: in perfumery, in cosmetics productions, pharmaceutical production, in food and in agriculture. One of the most important derivative of limonene is perillyl alcohol, which is used in the treatment of cancer, including breast, lung, liver and skin cancer. Similar properties have carveol [19].

Fraile et al. [20] described epoxidation olefins, among other, limonene. As the catalyst was used silica gel 60 treated with $\mathrm{Ti}(\mathrm{OiPr})_{4}$ and as the oxidizing agent t-butyl hydroperoxide. The epoxidations were performed at the room temperature, at the molar ratio of limonene to TBHP $=3: 1$. During these studies the selectivity of epoxide compound was $90 \%$, at the ratio of 1,2-epoxylimonene to 8,9 epoxylimonene $7: 1$.

Herrero et al. [21] described the catalytic epoxidation of limonene with hydrogen peroxide, among others, over zeolite Ti-beta (content of $\mathrm{TiO}_{2}$ was $2.6 \mathrm{wt} \%$ ). The reaction was carried out at $70{ }^{\circ} \mathrm{C}$, at the rate of limonene/hydrogen peroxide $(35 \%)=4$, and as the solvent acetone was used. After the reaction time of $7 \mathrm{~h}$, the conversion of hydrogen peroxide was $71.51 \%$, at the selectivity of epoxide $22.94 \%$.

Guidotti et al. [22] described epoxidation of six unsaturated cyclic terpenes (also limonene) over five titanium containing silicates: Ti-MCM-41, ordered titaniumgrafted mesoporous silica, $\mathrm{Ti}-\mathrm{SiO}_{2}$ Davison, nanoordered titanium-grafted porous silica, $\mathrm{Ti}-\mathrm{SiO}_{2}$ Aerosil, nonporous pyrogenic titanium-grafted silica, MST, nonordered in-framework mesoporous material, and $\mathrm{TiO}_{2}-\mathrm{SiO}_{2}$ Grace, commercial amorphous porous mixed oxide. The epoxidation was carried out at $90{ }^{\circ} \mathrm{C}$ for $24 \mathrm{~h}$, as the solvent acetonitrile was used and as the oxidizing agent t-butyl hydroperoxide (the molar ratio oxidant : terpene was 1:1). The Ti content in the catalysts changed from 1.88 to $1.40 \mathrm{wt} \%$. Good performances were obtained on the commercial mixed oxide (selectivity of the catalyst $75 \%$ ) and also on the three grafted silicas (for the Ti-MCM-41 selectivity of the catalyst was 90\%). These studies showed that the porosity features do not affect the catalytic performances noticeably and the use of an ordered mesoporous materials is not strictly required.

Wu et al. [23] described the utilization of Del-Ti-MWW catalyst in epoxidation of 1-hexene, 2-hexenes, cyclopentene, cyclooctene and cyclododecenes with hydrogen peroxide. The epoxidation was performed at $40{ }^{\circ} \mathrm{C}$ for cyclopentene and $60{ }^{\circ} \mathrm{C}$ for other compounds. Del-Ti-MWW catalyst proves to be superior to TS1, Ti-Beta, Ti-MWW and Ti-MCM-41 catalysts in the epoxidation of studied alkenes. Conversion over this catalyst of 1-hexene was $51.8 \%$, 2-hexenes $89.5 \%$, cyclopentene $58.9 \%$, cyclooctene $28.2 \%$ and cyclododecenes $20.7 \%$.

Guidotti et al. [24] described epoxidation of functionalized substrates (limonene, alfa-terpineol, carveol, and methyl linoleate) using mesoporous titanium-containing 
silica which underwent the silylation procedure. The silylation procedure did not influence considerably on the conversion of limonene, which over Ti-MCM-41 and after $1 \mathrm{~h}$ was 36\% (over silyled Ti-MCM-41 53\%), after 24 h 79\% (over silyled TiMCM-41 30\%), and selectivity of 1,2-epoxylimonene was practically unchanged and amounted to $80 \%$ (over silyled Ti-MCM-41 76\%). Over $\mathrm{SiO}_{2}$ containing $\mathrm{Ti}$ and after $1 \mathrm{~h}$, the conversion of limonene amounted to 37\% (over silylated Ti-MCM-41 $38 \%$ ), after $24 \mathrm{~h} 75 \%$ (over silylated $\mathrm{SiO}_{2}$ containing $\mathrm{Ti} 88 \%$ ), and the selectivity of 1,2-epoxylimonene was practically unchanged and amounted to $80 \%$ (over silylated $\mathrm{SiO}_{2}$ containing $\mathrm{Ti} 84 \%$ ). These studies showed that the effect of silylation was more pronounced on Ti-MCM-41 than with low-surface area $\mathrm{Ti}-\mathrm{SiO}_{2}$, and it was shown that the catalytic performances are strongly dependent on the nature of the reactant.

Guidotti et al. [25] described obtaining of 1,2-epoxylimonene over series TiMCM-41 catalysts with different hydrophilic/hydrophobic character, prepared by the post-synthesis silylation with hexamethyldisilazane. TBHP was used as the oxidizing agent. A maximum yield of 1,2-epoxylimonene was obtained over partially silylated catalyst with a surface coverage of $55 \%$. The reaction was performed in ethyl acetate as the solvent, at $90{ }^{\circ} \mathrm{C}$, at the molar ratio of TBHP/ limonene $=1.1$. The utilization of silylated Ti-MCM-41 catalyst allowed to obtain higher conversion of limonene (increase from 78 to $92 \%$ ). In some cases, an increase in selectivity of 1,2-epoxylimonene was observed from 76 to $85 \%$.

Gallo et al. [26] synthesized a series of niobium catalysts by post-synthesis modification of a commercial silica. These catalysts displayed an excellent performance in the epoxidation of limonene using hydrogen peroxide as oxidant-conversion of limonene up to $78 \%$ and selectivity of 1,2-epoxylimonene $98 \%$.

Kholdeeva [27] described epoxidation of limonene over mesoporous silicas containing metals other than titanium, e.g. Nb, Ta, W, Mn and Co. Niobiumcontaining MSU-X efficiently catalyzed the selective oxidation of limonene at the equimolecular content of hydrogen peroxide. At the beginning of the reaction the selectivity of 1,2-peoxylimonene was about $100 \%$ but then dropped to $70 \%$ due to formation of diepoxide (1,2-8,9-dipeoxide). During the epoxidation, no allylic oxidation was observed (carvone and carveol formation). With TBHP the reaction was slow and produced mainly 1,2-epoxylimonene.

Charbonneau et al. [28] studied epoxidation of limonene over Ti-SBA-16 catalysts prepared using two different post grafting techniques. During the studies, the influence of temperature, concentration of TBHP and solvent polarity were examined. When the process was carried out at $75{ }^{\circ} \mathrm{C}$ in acetonitrile using TBHP/ limonene molar ratio of $11 / 6$, the conversion of limonene reached $80 \%$ and the selectivity of 1,2-epoxylimonene oxide amounted to $79 \%$ for both impregnation methods using Ti-SBA-16 with a $\mathrm{Ti} / \mathrm{Si}$ atomic ratio of $7.3 \%$.

Cagnoli et al. [29] conducted research on limonene epoxidation using Ti-MCM41 catalyst. They synthesized the Ti-MCM-41 by the sol-gel method. The reaction was carried out at $70{ }^{\circ} \mathrm{C}$. As the solvent they used an acetonitrile and as an oxidant $35 \mathrm{wt} \% \mathrm{H}_{2} \mathrm{O}_{2}$. Cagnoli et al. received different limonene epoxidation products: 1,2epoxylimonene and 8,9-epoxylimonene with selectivity of $60 \mathrm{~mol} \%$, carvone and 
carveol with a selectivity of $20 \mathrm{~mol} \%$, diepoxylimonene and glycols with the selectivity of $10 \mathrm{~mol} \%$. Limonene conversion amounted to $50 \mathrm{~mol} \%$.

Bonon et al. [30] also performed studies on limonene epoxidation. As the reaction promoter they used $\mathrm{Al}_{2} \mathrm{O}_{3}$. The epoxidation was carried out at $80{ }^{\circ} \mathrm{C}$. As a solvent, they used ethyl acetate and as the oxidant $70 \mathrm{wt} \%$ hydrogen peroxide. They obtained highly efficient oxidation of limonene with hydrogen peroxide promoted by aluminum oxide and ethyl acetate as a solvent. They obtained diepoxides $12 \mathrm{~mol} \%$ at reaction times $6 \mathrm{~h}$, also internal $(79.7 \mathrm{~mol} \%)$ and external $(8.3 \mathrm{~mol} \%)$ epoxides with very high yield. Limonene conversion was above $80 \mathrm{~mol} \%$.

Also in our team limonene oxidation was investigated. As the oxidants hydrogen peroxide and tert-butyl hydroperoxide were used. Oxidation was performed in the presence of TS-2, Ti-Beta, Ti-MCM-41 and Ti-MWW catalysts [18]. During the studies on the oxidation of limonene which were carried out in an autoclave at autogenic pressure at $140{ }^{\circ} \mathrm{C}$ and with hydrogen peroxide, it was visible that over the hydrophilic catalysts such as TS-2, Ti-MCM-41 and Ti-MWW, the selectivity of 1,2-epoxylimonene was lower than for the hydrophilic Ti-Beta catalyst. The TS-2, Ti-MCM-41 and Ti-MWW catalysts the selectivity of this compound amounted to from 50 to $57 \mathrm{~mol} \%$, and for Ti-Beta $83 \mathrm{~mol} \%$. For the examinations with TBHP the results were opposite. The hydrophilic Ti-Beta allowed to achieve the selectivity of the epoxide compound $33 \mathrm{~mol} \%$, and the hydrophobic catalysts (TS-2, Ti-MCM41 and Ti-MWW) from 67 to $79 \mathrm{~mol} \%$. The second main product in the processes which were performed in autoclaves with hydrogen peroxide or TBHP was perillyl alcohol which selectivity reached about 20-26 mol\%. During the studies performed at the atmospheric pressure a considerable decrease in selectivity of 1,2epoxylimonene was observed. The highest values of this selectivity amounted to $13 \mathrm{~mol} \%$ (TS-2, TBHP). It was also visible a considerable increase in the values of selectivity of perillyl alcohol, especially for oxidation with TBHP. For epoxidation with TBHP over Ti-MCM-41 and Ti-MWW catalysts it was possible to obtain selectivity of perillyl alcohol about 46-49 mol\%.

Also studies with other catalyst were carried out for example TS-1 and Ti-SBA15 with $60 \mathrm{wt} \%$ hydrogen peroxide as the oxidant $[31,32]$. Reaction parameters was as follows: temperature range $0-120{ }^{\circ} \mathrm{C}$, molar ratio limonene $/ \mathrm{H}_{2} \mathrm{O}_{2} 1: 2$ and in case TS-1-1:1 [32], solvent concentration $80 \mathrm{wt} \%$, and catalyst content $3 \mathrm{wt} \%$. The highest selectivity of 1,2-epoxylimonene was obtained at $0{ }^{\circ} \mathrm{C}$ in the case of TS-1 (91 $\mathrm{mol} \%)$ and Ti-SBA-15 (68 $\mathrm{mol} \%)$.

The aim of the study was to examine the possibility of conducting limonene epoxidation over the Ti-MWW and Ti-MCM-41 catalysts using t-butyl hydroperoxide as the oxidizing agent. The study aimed to determine the most favorable reaction conditions for the epoxidation of limonene over these catalysts (temperature, molar ratio of reactants, methanol concentration, amount of catalyst and reaction time) and these studies compare the activity for these two materials. The most favorable conditions for the limonene oxidation process were selected at the highest conversion of limonene and at high values of perillyl alcohol and carveol or one of these two products (due to the complexity of the process and the low yields of 1,2-epoxylimonene). Perillyl alcohol and carveol have found numerous applications in medicine, among others, therefore this direction seems to be the 
most beneficial. The study also presents the characteristization of both materials based on instrumental research. The use of TBHP in these studies is justified because such studies in a wide range of changes in various technological parameters have not been presented so far. Only preliminary tests were conducted, which were carried out in much larger in terms of volume of equipment, under constant conditions and for Ti-MCM-41 and Ti-MWW catalysts differing in composition. The studies of other researchers showed that the studied by us process mainly caused formation of 1,2-epoxylimonene-thus the novelty of our studies is showing the possibility of formation of perillyl alcohol and carveol in reaction limonene with TBHP over Ti-MCM-41 and Ti-MWW catalysts.

\section{Materials and methods}

\section{Raw materials}

The following raw materials were used for the studies on limonene oxidation process: natural limonene obtained from orange peels, methanol (analytical grade, Chempur Poland), t-butyl hydroperoxide (5.5 M in decane, Sigma-Aldrich) and titanium silicate catalysts Ti-MWW and Ti-MCM-41 obtained by our team. In the gas chromatography method, the following compounds were used as patterns: $\mathrm{R}-(+)$-Limonene (analytical grade, sigma-Aldrich), 1,2-limonene oxide (97\% mixture cis and trans, Sigma-Aldrich), L-carveol ( $\geq 99 \%$ mixture of cis and trans, Sigma-Aldrich), S-(-) perillyl alcohol ( $\geq 95 \%$, sigma-Aldrich), and (1S,2S,4R)$(+)$ - limonene 1,2-diol ( $\geq 97 \%$, Sigma-Aldrich).

\section{Limonene obtaining methods}

In the experimental part, first we studied the extraction of limonene from orange peels in the following ways: simple distillation and steam distillation. Peels before placing in the distillation flask were pulverized using a mixer by adding water. Water and orange pulp were put in the 3- or 2-necked flask with a capacity of $5000 \mathrm{~cm}^{3}$, equipped with a heating coat and a condenser. The orange oil distillation was continued until the organic phase in the distillate was increased. As distillate 2 layers: the top —organic (orange oil) and bottom—water were obtained. The layers were separated by freezing to remove water from the product. Then the purity of orange oil was tested by the GC method. Fig. 1 presents the chromatogram of the obtained from orange peels oil.

\section{Obtaining the Ti-MWW catalyst}

In the synthesis of the Ti-MWW catalyst, the following raw materials were used: TBOT- $\mathrm{Ti}(\mathrm{OBu})_{4}$, hexamethyleneimine-HMI, boric acid, and fumed silica Cab-oSil M5. The catalyst was synthesized by the method of Wu et al. [33]. The process of preparation was divided into a few steps: the synthesis of the Ti-MWW gel, crystallization of the obtained gel, washing the crystals with deionized water to $\mathrm{pH}$ 


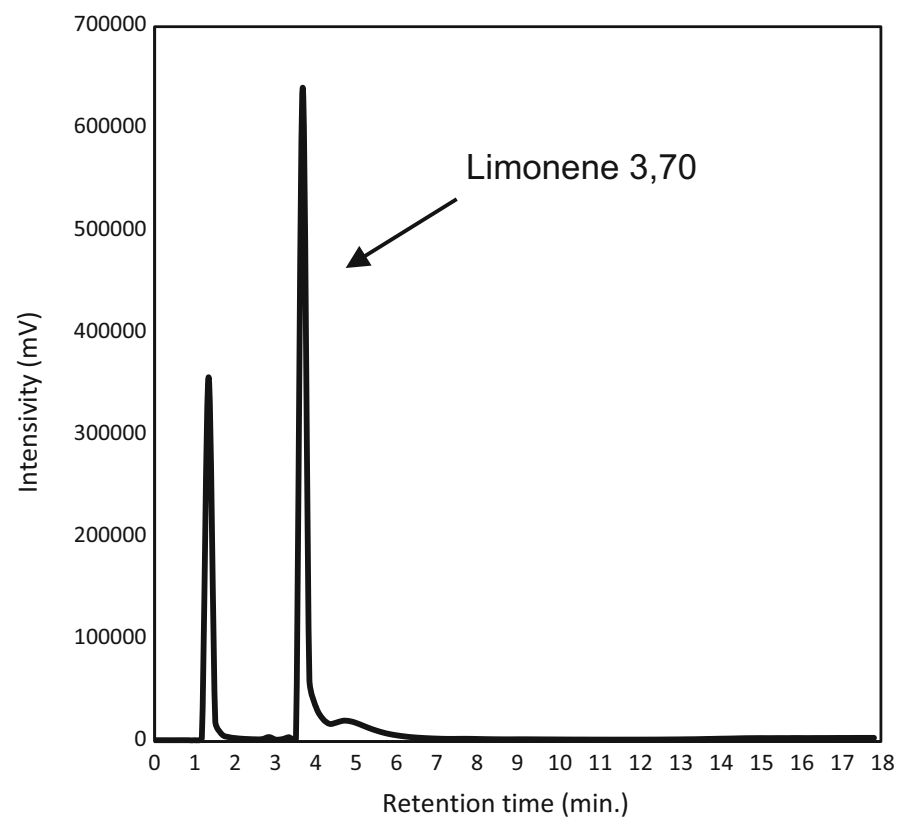

Fig. 1 Organic layer gas chromatogram from simple distillation of limonene-retention time 3.70 corresponds to limonene, the solvent was acetone

9, drying, acid treatment to remove boron and calcination [24]. The obtained catalyst was characterized by the following methods: IR and UV-VIS-Figs. 2 and 3. Also Ti-MWW was characterized by X-ray diffraction method (XRD) (Fig. 4)-

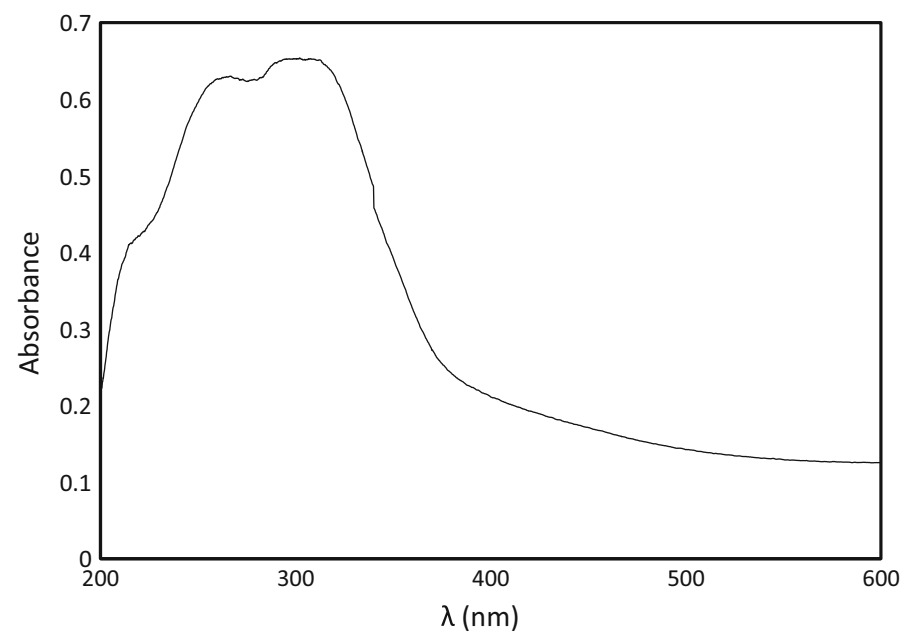

Fig. 2 UV-VIS spectra of Ti-MWW catalyst 


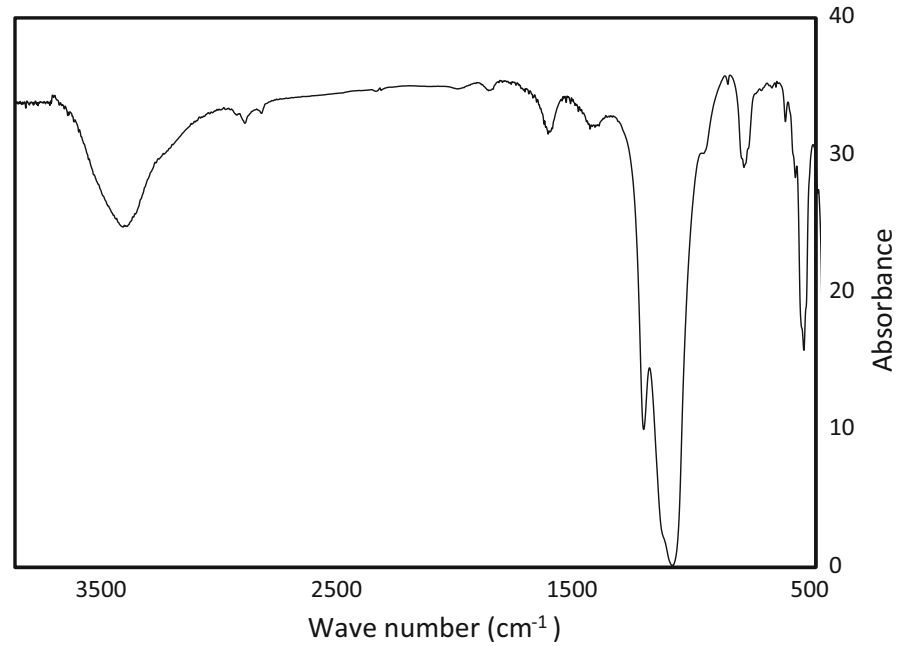

Fig. 3 IR spectra of Ti-MWW catalyst

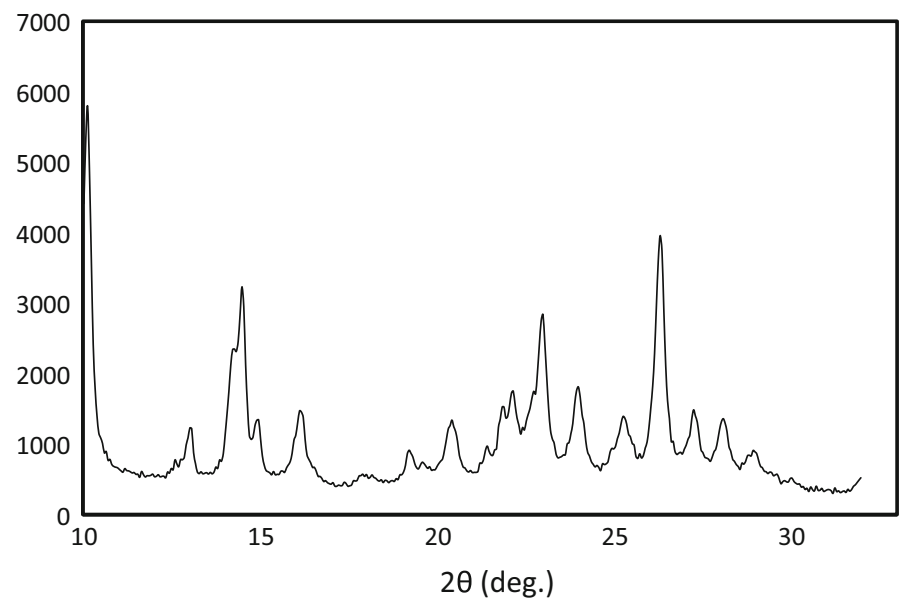

Fig. 4 XRD patterns of Ti-MWW catalyst

the diffraction peaks were consistent with the literature [33] and by SEM method (Fig. 5).

FTIR studies were carried out on JASCO FT/IR—430 apparatus. Tests were carried out by the method of solid in solid (in $\mathrm{KBr}$ ). The parameters of the apparatus are as follows: measuring range $1500-400 \mathrm{~cm}^{-1}$, sensitivity 50 , and the threshold of absolute 85.833. UV-VIS studies were carried out on a SPECORD M40 type V-530 scanning instrument at a speed of $200 \mathrm{~nm} / \mathrm{min}$, a measuring range 600-200 $\mathrm{nm}$ in steps of measuring at $1 \mathrm{~nm}$ and the width of the resulting bandwidth of $2.0 \mathrm{~nm}$. The $\mathrm{X}$-ray diffraction (XRD) pattern of the catalysts were recorded by a PANalytical Empyrean X-ray diffractometer using $\mathrm{Cu} \mathrm{K} \alpha(\lambda=0.154 \mathrm{~nm})$ as the radiation source 


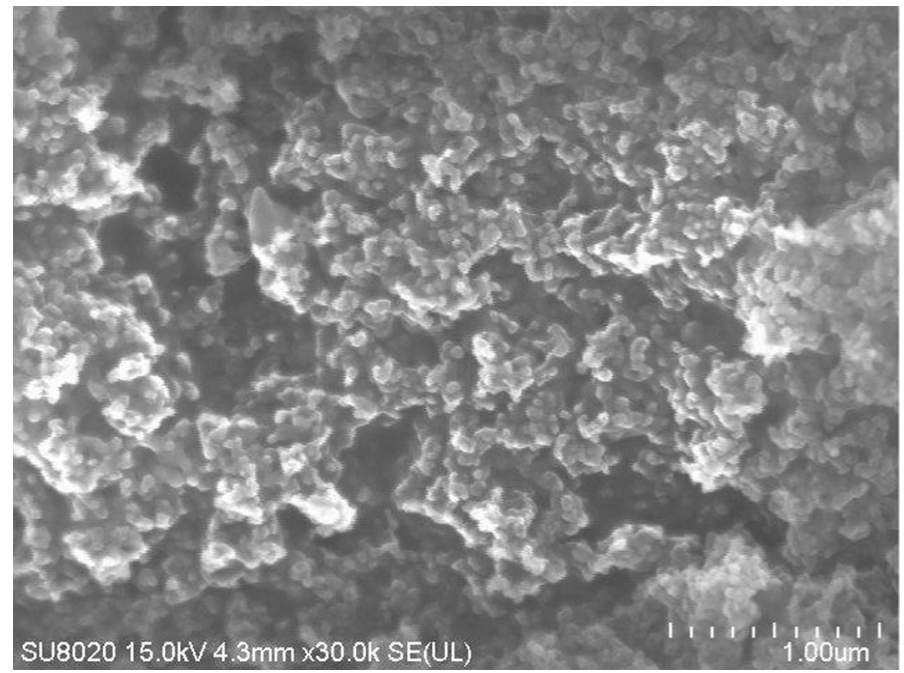

Fig. 5 SEM spectra of Ti-MWW catalyst

in the $2 \theta$ range $10-35^{\circ}$ with a step size of 0.05 . Scanning electron microscope (SEM) micrographs were obtained using an ultra-high resolution field emission scanning electron microscope (Hitachi UHR FE-SEM SU8020, Tokyo, Japan) equipped with the secondary electron (SE) detectors and an energy dispersive X-ray detector (EDX). On the basis of EDX measurements the quantitative content of titanium in the catalysts was determined.

The UV-VIS spectra of Ti-MWW samples showed characteristic absorption bands at $210-220 \mathrm{~nm}$ [34], which is ascribed to the presence of $\mathrm{Ti}^{4+}$ species isolated in the zeolite framework [35] and corresponds to a charge transfer from the oxygen ligands $\mathrm{O}^{2-}$ to $\mathrm{Ti}^{4+}$. The band around $260 \mathrm{~nm}$ is attributed to the octahedral Ti species on the external surface of zeolite [36, 37]. A band above $300 \mathrm{~nm}$ is also visible, whose presence is connected with the presence of anatase in the studied sample [36, 37]. The FT-IR spectra of Ti-MWW samples showed the distinctive IR band at $960-970 \mathrm{~cm}^{-1}$ that is usually concerned as the fingerprint region of the tetrahedrally coordinated Ti species in titanosilicates [38]. The accurate assignment of the $960 \mathrm{~cm}^{-1}$ band was debated. First, it was attributed to the Si-O stretching vibration perturbed by the neighboring $\mathrm{Ti}^{4+}$ ions [39]. Second, it was attributed to the stretching vibration of the $\mathrm{Si}-\mathrm{O}$ bond in $\mathrm{Si}-\mathrm{O}-\mathrm{Ti}$ bridges or to the $\mathrm{Ti}-\mathrm{O}-\mathrm{Si}$ stretch $[40,41]$. The assignments of this band are also complicated by the fact that hydroxyls and silanol groups of defect sites absorb in the same range. Camblor et al. [42] proposed that the $960 \mathrm{~cm}^{-1}$ band is a $\mathrm{Si}-\mathrm{O}$ vibration associated with framework defects. Practical, a mixture of $\mathrm{Ti}(\mathrm{OSi})_{4}, \mathrm{Ti}(\mathrm{OSi})_{3} \mathrm{OH}$, and $\mathrm{Ti}(\mathrm{OSi})_{2}(-$ $\mathrm{OH})_{2}$ species are possible in titanosilicates, as proposed by the theoretical calculations that partial hydrolysis of the Ti-O-Si bridges in framework-substituted silica is energetically feasible [42]. The Ti content in the obtained catalyst was 1.0 wt\%. A full characteristic of this catalyst is presented in our previous work [4]. 


\section{Obtaining of the Ti-MCM-41 catalyst}

Ti-MCM-41 catalyst was prepared by the method of Schumacher et al. [43]. Into the glass reactor equipped with mechanical stirred was placed hexadecyltrimethylammonium bromide, deionized water, $33 \mathrm{wt} \%$ ammonia water solution and ethanol. The solution then was mixed for $30 \mathrm{~min}$. After that, tetrabutyl o-titanate and tetraethyl o-silicate was dropped to the reactor under vigorous stirring. Afterwards, the content of the reactor was mixed for $4 \mathrm{~h}$. The solid product was washed with deionized water and methanol, next was dried in $120{ }^{\circ} \mathrm{C}$ for $6 \mathrm{~h}$ and then calcined in air at $550{ }^{\circ} \mathrm{C}$ for $8 \mathrm{~h}$. The catalyst was characterized by the UV-VIS and IR methods presented in Figs. 6 and 7. The X-ray diffraction and SEM methods were also performed for the Ti-MCM-41 catalyst (Figs. 8, 9). The diffraction peaks were compared with the literature data [44].

The UV-VIS spectra of Ti-MCM-41 samples showed characteristic absorption bands at $210-220 \mathrm{~nm}$ which is ascribed to the $\mathrm{Ti}^{4+}$ species isolated in the zeolite framework. The band around $260 \mathrm{~nm}$ attributed to the octahedral Ti species on the external surface of zeolite and the band above $300 \mathrm{~nm}$ connected with the presence of anatase are present in the spectrum of in the studied sample [36, 37]. Comparing the spectra from Ti-MCM-41 and Ti-MWW can conclude that Ti species have been incorporated into the structure of the catalyst. The FTIR spectra of Ti-MCM-41 catalyst shown characteristic band at $960 \mathrm{~cm}^{-1}$ which correspond to the Ti species in tetrahedral coordination in titanosilicates, the other bands are characteristic of the silicates. The FTIR spectra of the Ti-MCM-41 and Ti-MWW are consistent with the literature. Characteristic bands coming from Ti species can be seen in both spectra. Ti content in obtained catalyst was $1.33 \mathrm{wt} \%$.

A full characteristization of this catalyst is present in our previous works $[9,44]$.

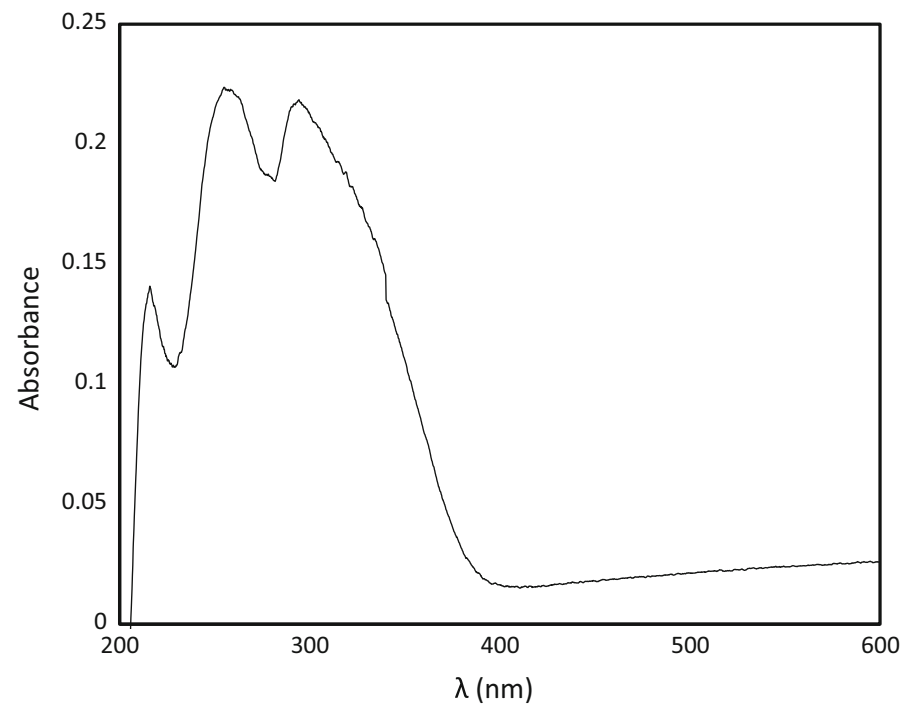

Fig. 6 UV-VIS spectra of Ti-MCM-41 catalyst 


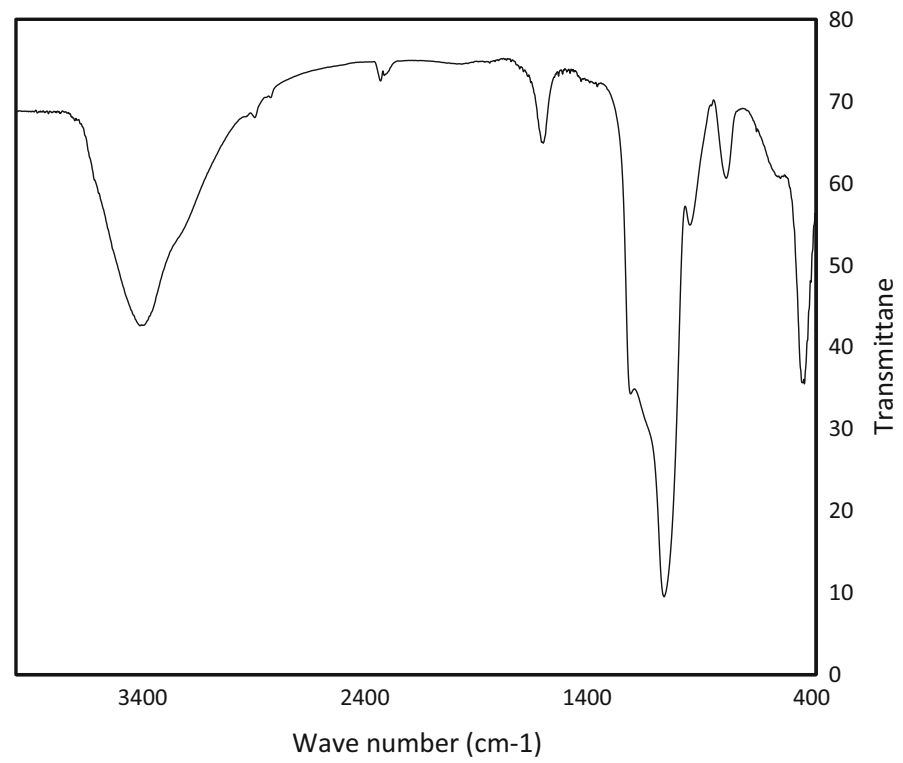

Fig. 7 IR spectra of Ti-MCM-41 catalyst

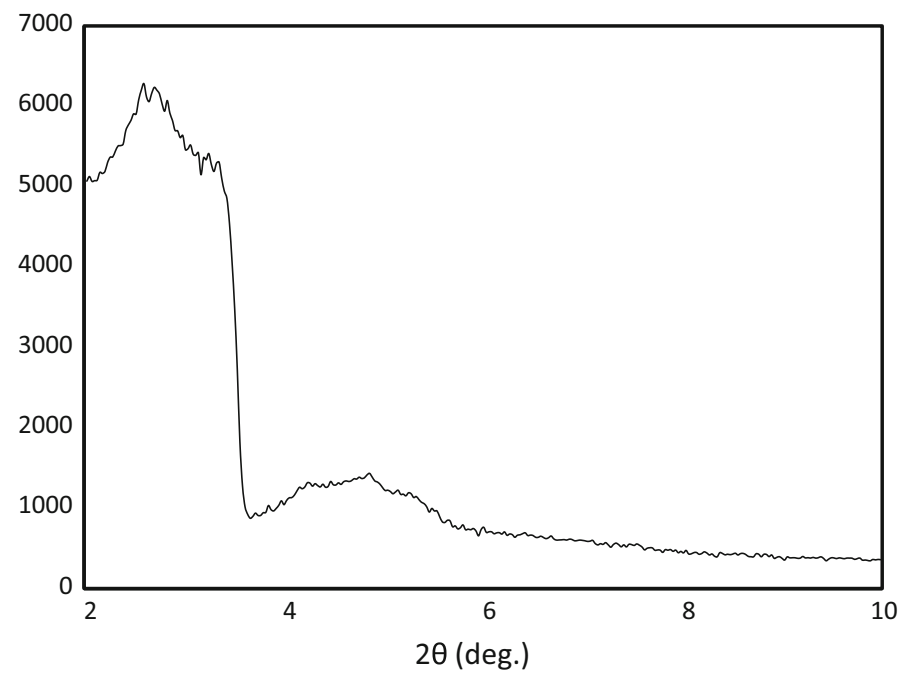

Fig. 8 XRD pattern of Ti-MCM-41 catalyst

\section{The method of limonene oxidation}

The activity of the obtained Ti-MWW and Ti-MCM-41 catalysts was investigated. In the limonene epoxidation, we used natural limonene (obtained from orange peels), methanol as the solvent and as the oxidant: tert-butyl hydroperoxide (TBHP). The process of limonene epoxidation was carried out at the following ranges of 


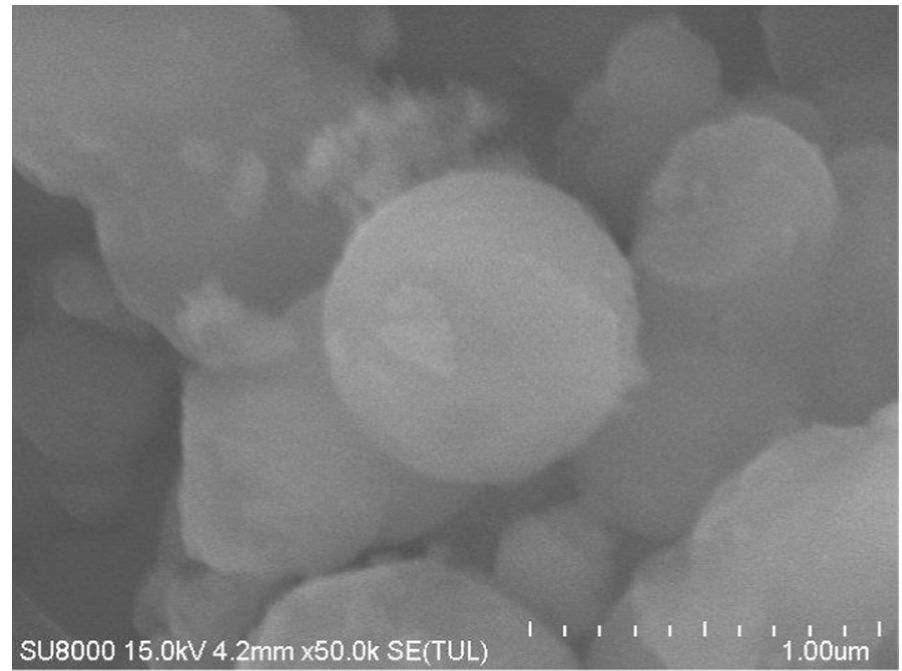

Fig. 9 SEM spectra of Ti-MCM-41 catalyst

variable parameters: reaction temperature $20-140{ }^{\circ} \mathrm{C}$, the molar ratio: limonene/ TBHP 1:1-5:1, solvent concentration (methanol) 60-80 wt \%, the amount of catalysts Ti MWW and Ti-MCM-41 1-6 wt\%, reaction time 6-24 h, intensity of stirring $500 \mathrm{rpm}$. Limonene epoxidation was carried out in a glass flask with the volume of $50 \mathrm{~cm}^{3}$, equipped with the reflux condenser (in lower temperatures) and in the high-pressure apparatus BERGHOFF 100 (for higher temperature) equipped with the TEFLON insert with the capacity of $100 \mathrm{~cm}^{3}$. The maximum amount of charge in the autoclave was about $10 \mathrm{~g}$. The maximum ratio of the volume of the reaction mixture to the volume of the PTFE liner was about 0.1. An appropriate amount of catalyst was first placed in the autoclave or in the glass flask, then the solvent and limonene was added and at the end was oxidizer was added to a mixture. Then the reaction mixture was mixed and heated for $6 \mathrm{~h}$, afterwards a sample was taken, centrifuged and investigated by the gas chromatography method (GC). The conditions of the GC method were as follows: the capillary column-Quadrex 007WAX $-0.32 \mathrm{~mm}, 30 \mathrm{~m}, 0.5 \mu \mathrm{m}$ filled with polyethylene glycol, detector FIDtemperature $250{ }^{\circ} \mathrm{C}$, dispenser-temperature $250{ }^{\circ} \mathrm{C}$, temperature program- $60{ }^{\circ} \mathrm{C}$ for $3 \mathrm{~min}, 15^{\circ} \mathrm{C} / 1 \mathrm{~min}$ increase to $200{ }^{\circ} \mathrm{C}$, then isothermal for $5 \mathrm{~min}$, hydrogen flow-50 kPa, helium flow-45 kPa, air flow-70-80 kPa and volume of the injection-0.1 ml.

The main functions describing the process were calculated: $C_{L}$-limonene conversion, $\mathrm{Y}_{\mathrm{EL}}$-yield of 1,2-epoxylimonene, $\mathrm{Y}_{\mathrm{ELD}}$-yield of 1,2-epoxylimonene diol, $\mathrm{Y}_{\mathrm{CN}}$-yield of carvone, $\mathrm{Y}_{\mathrm{CL}}$-yield of carveol, $\mathrm{Y}_{\mathrm{AP}}$-yield of perillyl alcohol. The main functions describing the process were calculated on the basis the following formulas: 


$$
\begin{gathered}
\mathrm{Y}_{\text {Product } / \mathrm{L}}=\frac{\text { Amount of moles of product }}{\text { Amount of moles of limonene introduced into reactor }} \times 100(\mathrm{~mol} \%) \\
\mathrm{C}_{\mathrm{L}}=\frac{\text { Amount of moles of limonene consumed }}{\text { Amount of moles of limonene introduced into reactor }} \times 100(\mathrm{~mol} \%)
\end{gathered}
$$

\section{Results and discussion}

As the first parameter temperature was studied. For all catalyst the range of studied temperatures was the same and amounted to $20-140{ }^{\circ} \mathrm{C}$. The next parameters were as follows: the molar ratio of limonene : TBHP 1:1, amount of solvent $80 \mathrm{wt} \%$, amount of catalyst $3 \mathrm{wt} \%$, the reaction time $6 \mathrm{~h}$, and the intensity of stirring $500 \mathrm{rpm}$. The results of the studies are presented in Table 1.

Over the Ti-MCM-41 catalyst the conversion of limonene achieved 0 mol\% to $60{ }^{\circ} \mathrm{C}$. Above this temperature the conversion raised to $94.7 \mathrm{~mol} \%\left(130{ }^{\circ} \mathrm{C}\right)$. At $140{ }^{\circ} \mathrm{C}$, a considerable decrease in the value of this function to $63.6 \mathrm{~mol} \%$ is observed. This phenomenon is mainly connected with the polymerization reactions which occur at high temperatures. The yield of 1,2-epoxylimonene over this catalyst was very low and the maximum value of this function was obtained for $140{ }^{\circ} \mathrm{C}$. The main product of this process was perillyl alcohol which yield achieved the maximum value $130{ }^{\circ} \mathrm{C}(58.6 \mathrm{~mol} \%)$. The second product which was formed with high yield was carveol, its maximum value of yield was archived for $130{ }^{\circ} \mathrm{C}$ $(28 \mathrm{~mol} \%)$. It shows that the main directions of limonene oxidation were allylic oxidations (hydroxylations) at positions 6 and 7 not epoxidation at position 1,2. The possibility of such directions in the limonene oxidation process were described previously by us $[23,24]$.

Over the Ti-MWW catalyst the conversions of limonene were considerably lower, the highest conversion of limonene was obtained for $140{ }^{\circ} \mathrm{C}(55.6 \mathrm{~mol} \%)$. The yield of 1,2-epoxylimonene was low and achieved the highest value at $120{ }^{\circ} \mathrm{C}-$ $2.9 \mathrm{~mol} \%$. The highest values of yield were obtained for carveol at $140{ }^{\circ} \mathrm{C}-$ $33.1 \mathrm{~mol} \%$. Also formation of carvone was observed-the highest value was obtained for $140{ }^{\circ} \mathrm{C}$ and it amounted to $15.4 \mathrm{~mol} \%$. Perillyl alcohol yield was not so high as over Ti-MCM-41 catalyst, and amounted to $16.6 \mathrm{~mol} \%\left(90^{\circ} \mathrm{C}\right)$.

Because the yield of 1,2-epoxylimonene was low, we decided to take into account mainly the conversion of limonene as the function which values will decide about the choosing the appropriate parameter to the next stage of studies. At high values of conversion of limonene, it is possible to obtain also high values of yield of perillyl alcohol and carveol, or one from these two very valuable compounds. The highest limonene conversion was obtained at $130{ }^{\circ} \mathrm{C}$ for the Ti-MCM-41 and at $140{ }^{\circ} \mathrm{C}$ for the Ti-MWW catalyst. Thus, these temperatures were chosen to the next of studies.

Then the studies on the influence of the molar ratio of limonene to TBHP in range 1:1-5:1 were performed. The other parameters assumed the following values: $130{ }^{\circ} \mathrm{C}$ for Ti-MCM-41 catalyst and $140{ }^{\circ} \mathrm{C}$ for the Ti-MWW, amount of solvent 80 
Table 1 The influence of temperature

\begin{tabular}{|c|c|c|c|c|c|c|}
\hline $\begin{array}{l}\text { Temperature } \\
\left({ }^{\circ} \mathrm{C}\right)\end{array}$ & $\begin{array}{l}\mathrm{Y}_{\mathrm{EL}} \\
(\mathrm{mol} \%)\end{array}$ & $\begin{array}{l}Y_{\text {ELD }} \\
(\mathrm{mol} \%)\end{array}$ & $\begin{array}{l}\mathrm{Y}_{\mathrm{CN}} \\
(\mathrm{mol} \%)\end{array}$ & $\begin{array}{l}\mathrm{Y}_{\mathrm{CL}} \\
(\mathrm{mol} \%)\end{array}$ & $\begin{array}{l}\mathrm{Y}_{\mathrm{AP}} \\
(\mathrm{mol} \%)\end{array}$ & $\begin{array}{l}\mathrm{C}_{\mathrm{L}} \\
(\mathrm{mol} \%)\end{array}$ \\
\hline \multicolumn{7}{|c|}{ Studies with Ti-MCM-41 } \\
\hline 20 & 0.0 & 0.0 & 0.0 & 0.0 & 0.0 & 0.0 \\
\hline 30 & 0.0 & 0.0 & 0.0 & 0.0 & 0.0 & 0.0 \\
\hline 40 & 0.0 & 0.0 & 0.0 & 0.0 & 0.0 & 0.0 \\
\hline 50 & 0.0 & 0.0 & 0.0 & 0.0 & 0.0 & 0.0 \\
\hline 60 & 0.0 & 0.0 & 0.0 & 0.0 & 0.0 & 0.0 \\
\hline 70 & 0.0 & 0.0 & 0.0 & 0.0 & 0.9 & 0.9 \\
\hline 80 & 0.0 & 1.4 & 0.0 & 0.8 & 9.8 & 12.1 \\
\hline 90 & 0.0 & 4.4 & 0.0 & 8.3 & 21.2 & 33.8 \\
\hline 100 & 0.0 & 1.5 & 0.0 & 9.4 & 24.1 & 35.0 \\
\hline 110 & 0.1 & 1.9 & 0.0 & 22.2 & 54.1 & 78.3 \\
\hline 120 & 0.0 & 3.3 & 0.0 & 9.1 & 18.4 & 30.8 \\
\hline 130 & 1.5 & 6.2 & 0.5 & 28.0 & 58.6 & 94.7 \\
\hline 140 & 2.4 & 12.6 & 0.4 & 15.2 & 33.0 & 63.6 \\
\hline \multicolumn{7}{|c|}{ Studies with Ti-MWW } \\
\hline 20 & 0.0 & 0.0 & 0.2 & 3.7 & 0.0 & 3.9 \\
\hline 30 & 0.0 & 0.0 & 0.6 & 3.7 & 0.0 & 4.3 \\
\hline 40 & 0.0 & 0.0 & 0.6 & 3.1 & 0.0 & 3.7 \\
\hline 50 & 0.0 & 0.0 & 0.7 & 3.8 & 0.0 & 4.7 \\
\hline 60 & 0.0 & 0.0 & 3.2 & 9.9 & 0.1 & 13.2 \\
\hline 70 & 0.0 & 0.0 & 2.0 & 8.7 & 0.9 & 11.6 \\
\hline 80 & 0.0 & 0.0 & 3.8 & 2.0 & 8.9 & 14.6 \\
\hline 90 & 0.0 & 0.0 & 7.4 & 10.5 & 16.6 & 34.6 \\
\hline 100 & 0.0 & 0.0 & 9.1 & 20.1 & 7.1 & 36.3 \\
\hline 110 & 0.0 & 0.0 & 11.7 & 26.2 & 8.7 & 46.6 \\
\hline 120 & 2.9 & 0.0 & 7.2 & 12.4 & 4.2 & 26.7 \\
\hline 130 & 2.2 & 0.0 & 12.0 & 22.3 & 6.1 & 42.6 \\
\hline 140 & 1.5 & 0.0 & 15.4 & 33.1 & 5.8 & 55.6 \\
\hline
\end{tabular}

wt \%; amount of catalyst $3 \mathrm{wt} \%$; reaction time $6 \mathrm{~h}$, and the intensity of stirring $500 \mathrm{rpm}$. The obtained results are presented in Table 2.

The studies over the Ti-MCM-41 catalyst showed that conversion of limonene decreased from 94.7 to $47.8 \mathrm{~mol} \%$. The highest yield from the products was achieved for perillyl alcohol, and this function changed from 58.6 to $35.3 \mathrm{~mol} \%$ in the studied range of molar ratios of reactants. Carveol was also formed with high yield, which changed from 28.0 to $10.5 \mathrm{~mol} \%$. 1,2-epoxylimonene formation (yield $1.5 \mathrm{~mol} \%$ ) was only observed for the equimolecular ratio of reactants.

Over Ti-MWW catalyst the conversions of limonene were considerably lower and changed from 55.8 to $15.3 \mathrm{~mol} \%$. The highest yield of perillyl alcohol was 
Table 2 The influence of the molar ratio limonene/TBHP

\begin{tabular}{lllllll}
\hline Molar ratio limonene/TBHP & $\begin{array}{l}\mathrm{Y}_{\mathrm{EL}} \\
(\mathrm{mol} \%)\end{array}$ & $\begin{array}{l}\mathrm{Y}_{\mathrm{ELD}} \\
(\mathrm{mol} \%)\end{array}$ & $\begin{array}{l}\mathrm{Y}_{\mathrm{CN}} \\
(\mathrm{mol} \%)\end{array}$ & $\begin{array}{l}\mathrm{Y}_{\mathrm{CL}} \\
(\mathrm{mol} \%)\end{array}$ & $\begin{array}{l}\mathrm{Y}_{\mathrm{AP}} \\
(\mathrm{mol} \%)\end{array}$ & $\begin{array}{l}\mathrm{C}_{\mathrm{L}} \\
(\mathrm{mol} \%)\end{array}$ \\
\hline Studies with Ti-MCM-41 & & & & & & \\
$1: 1$ & 1.5 & 6.2 & 0.5 & 28.0 & 58.6 & 94.7 \\
$2: 1$ & 0.0 & 3.7 & 0.0 & 21.4 & 37.5 & 62.7 \\
$3: 1$ & 0.0 & 7.8 & 0.0 & 16.5 & 49.2 & 73.4 \\
$4: 1$ & 0.0 & 0.0 & 0.0 & 21.1 & 52.9 & 73.9 \\
$5: 1$ & 0.0 & 2.0 & 0.0 & 10.5 & 35.3 & 47.8 \\
Studies with Ti-MWW & & & & & & \\
$1: 1$ & 1.5 & 0.0 & 15.4 & 33.1 & 5.8 & 55.8 \\
$2: 1$ & 0.0 & 0.0 & 0.0 & 7.8 & 18.6 & 26.4 \\
$3: 1$ & 0.0 & 0.0 & 0.0 & 11.3 & 30.9 & 42.2 \\
$4: 1$ & 0.0 & 0.0 & 0.1 & 5.2 & 13.2 & 18.5 \\
$5: 1$ & 0.0 & 0.0 & 1.3 & 2.6 & 11.4 & 15.3 \\
\hline
\end{tabular}

obtained for the molar ratio of reactants amounted to $3: 1(30.9 \mathrm{~mol} \%)$. The highest yield of carveol was obtained for the equimolecular ratio of reactant and it amounted to $33.1 \mathrm{~mol} \%$. The same as for the MCM-41 catalyst, 1,2-epoxylimonene was formed at the equimolecular ratio of reactants and the yield of this compound amounted to $1.5 \mathrm{~mol} \%$.

Taking into account the values of conversion of limonene as the most beneficial was taken the equimolecular ratio of reactants.

In the next stage the studies on the influence of methanol concentration in the range of of 60-90 wt $\%$ were performed. The other parameters were as follows: $130{ }^{\circ} \mathrm{C}$ for Ti-MCM-41 catalyst and $140{ }^{\circ} \mathrm{C}$ for the Ti-MWW; molar ratio limonene : TBHP 1:1; amount of catalyst $3 \mathrm{wt} \%$; reaction time $6 \mathrm{~h}$, and the intensity of stirring $500 \mathrm{rpm}$. The obtained results are shown in Table 3.

Table 3 The influence of the amount of solvent (methanol)

\begin{tabular}{llllccc}
\hline The amount of solvent $(\mathrm{wt} \%)$ & $\begin{array}{l}\mathrm{Y}_{\mathrm{EL}} \\
(\mathrm{mol} \%)\end{array}$ & $\begin{array}{l}\mathrm{Y}_{\mathrm{ELD}} \\
(\mathrm{mol} \%)\end{array}$ & $\begin{array}{l}\mathrm{Y}_{\mathrm{CN}} \\
(\mathrm{mol} \%)\end{array}$ & $\begin{array}{l}\mathrm{Y}_{\mathrm{CL}} \\
(\mathrm{mol} \%)\end{array}$ & $\begin{array}{l}\mathrm{Y}_{\mathrm{AP}} \\
(\mathrm{mol} \%)\end{array}$ & $\begin{array}{l}\mathrm{C}_{\mathrm{L}} \\
(\mathrm{mol} \%)\end{array}$ \\
\hline Studies with Ti-MCM-41 & & & & & & \\
$\quad 60$ & 5.2 & 6.5 & 0.6 & 26.6 & 49.5 & 88.4 \\
70 & 5.1 & 8.8 & 4.2 & 28.4 & 45.4 & 91.9 \\
80 & 1.5 & 6.2 & 0.5 & 28.0 & 58.6 & 94.7 \\
90 & 0.0 & 0.7 & 0.0 & 0.0 & 78.7 & 79.4 \\
Studies with Ti-MWW & & & & & & \\
60 & 0.0 & 5.0 & 0.0 & 9.2 & 17.9 & 32.1 \\
70 & 0.0 & 5.0 & 0.0 & 14.2 & 39.1 & 58.2 \\
80 & 1.5 & 0.0 & 15.4 & 33.1 & 5.8 & 55.8 \\
90 & 0.0 & 0.0 & 0.0 & 1.3 & 11.8 & 13.1 \\
\hline
\end{tabular}


During the studies on the influence of methanol concentration over the Ti-MCM41 catalyst, it was also visible that over this catalyst, it is possible to obtain higher values of limonene conversion then over the Ti-MWW catalyst. Over the Ti-MCM41 catalyst this function changed from $88.4 \mathrm{~mol} \%$ (solvent concentration $60 \mathrm{wt} \%$ ) to $94.7 \mathrm{~mol} \%$ (solvent concentration $80 \mathrm{wt} \%$ ). The main product which was formed with the highest yield was perillyl alcohol. The yield of this alcohol changed from 49.5 to $78.7 \mathrm{~mol} \%$. The second main product was carveol, whose yield amounted to about $27-28 \mathrm{~mol} \%$ (for methanol concentrations 60-80 wt \%). The highest yield of 1,2-epoxylimonene was obtained for methanol concentrations 60-70 wt $\%$ and it amounted about $5 \mathrm{~mol} \%$.

Over the Ti-MWW catalyst, the conversion of limonene raised from 32.1 to $58.2 \mathrm{~mol} \%$ in the range of methanol concentrations 60-70 wt $\%$, next it decreased do $13.1 \mathrm{~mol} \%$ (methanol concentration $90 \mathrm{wt} \%$ ). The highest yield of perillyl alcohol was obtained for the methanol concentration of $70 \mathrm{wt} \%-39.1 \mathrm{~mol} \%$, and the highest yield of carveol was obtained for the methanol concentration of $80 \mathrm{wt} \%$ $33.1 \mathrm{~mol} \%$. 1,2-Epoxylionene was formed only at the methanol concentration amounted to $80 \mathrm{wt} \%$, and its yield was $1.5 \mathrm{~mol} \%$.

Taking into account the values of limonene conversion for the Ti-MCM-41 catalyst as the most beneficial was taken the methanol concentration of $80 \mathrm{wt} \%$. In case of Ti-MWW, the most beneficial methanol concentration amounted to $70 \mathrm{wt} \%$.

The next parameter which we were studied was amount of the catalyst in the range of $1-5 \mathrm{wt} \%$ for Ti-MCM-41 catalyst and 2-6 wt $\%$ for Ti-MWW catalyst. The other parameters were as follows: temperature $130{ }^{\circ} \mathrm{C}$ for Ti-MCM-41 catalyst and $140{ }^{\circ} \mathrm{C}$ for the Ti-MWW; molar ratio limonen : TBHP 1:1; amount of solvent TiMCM-41 $80 \mathrm{wt} \%$, Ti-MWW $70 \mathrm{wt} \%$; reaction time $6 \mathrm{~h}$, and the intensity of stirring $500 \mathrm{rpm}$. The results are shown in Table 4.

Table 4 The influence of amount of catalyst

\begin{tabular}{lllllll}
\hline The amount of catalyst (wt\%) & $\begin{array}{l}\mathrm{Y}_{\mathrm{EL}} \\
(\mathrm{mol} \%)\end{array}$ & $\begin{array}{l}\mathrm{Y}_{\mathrm{ELD}} \\
(\mathrm{mol} \%)\end{array}$ & $\begin{array}{l}\mathrm{Y}_{\mathrm{CN}} \\
(\mathrm{mol} \%)\end{array}$ & $\begin{array}{l}\mathrm{Y}_{\mathrm{CL}} \\
(\mathrm{mol} \%)\end{array}$ & $\begin{array}{l}\mathrm{Y}_{\mathrm{AP}} \\
(\mathrm{mol} \%)\end{array}$ & $\begin{array}{l}\mathrm{C}_{\mathrm{L}} \\
(\mathrm{mol} \%)\end{array}$ \\
\hline Studies with Ti-MCM-41 & & & & & & \\
1 & 0.0 & 9.7 & 5.8 & 5.4 & 0.7 & 21.5 \\
2 & 0.0 & 17.6 & 14.6 & 37.9 & 8.8 & 78.8 \\
3 & 1.5 & 6.2 & 0.5 & 28.0 & 58.6 & 94.7 \\
4 & 0.0 & 0.1 & 15.5 & 32.8 & 34.2 & 82.5 \\
5 & 0.0 & 0.1 & 43.1 & 38.1 & 5.9 & 87.1 \\
Studies with Ti-MWW & & & & & & 19.2 \\
2 & 0.0 & 1.9 & 9.6 & 10.4 & 41.1 \\
3 & 0.0 & 5.0 & 0.0 & 14.2 & 39.1 & 58.2 \\
4 & 0.0 & 0.9 & 1.0 & 14.4 & 36.7 & 53.0 \\
5 & 0.0 & 2.5 & 2.2 & 9.4 & 25.5 & 39.6 \\
6 & 0.0 & 2.0 & 2.1 & 11.6 & 21.4 & 37.1 \\
\hline
\end{tabular}


During the studies over the Ti-MCM-41 catalyst, the conversion generally raised with the increase of the catalyst content. The highest value of limonene conversion was obtained for the catalyst content amounted to $3 \mathrm{wt} \%(94.7 \mathrm{~mol} \%)$. Depending on the content of the catalyst, the main products were: for the content of the catalyst $2 \mathrm{wt} \%$ - carveol (yield $37.9 \mathrm{~mol} \%$ ), for the content of the catalyst $5 \mathrm{wt} \%$-carvone (yield $43.1 \mathrm{~mol} \%$ ). The highest yield of perillyl alcohol was obtained for the catalyst content of $3 \mathrm{wt} \%$ (58.6 mol\%). The 1,2-epoxylimonene yield amounted only $1.5 \mathrm{~mol} \%$ at the catalyst content $3 \mathrm{wt} \%$.

During the studies over Ti-MWW catalyst, the conversion of limonene raised from 41.1 to $58.2 \mathrm{~mol} \%$ during increasing the content of the catalyst from 1 to 3 $\mathrm{wt} \%$, and next decreased to $37.1 \mathrm{~mol} \%$. The highest yield was obtained for perillyl alcohol as $39.1 \mathrm{~mol} \%$ at the catalyst content $3 \mathrm{wt} \%$. Also carveol was during our studies, the yield of this compound was the highest for the catalyst content $4 \mathrm{wt} \%$ and amounted to about $14-33.1 \mathrm{~mol} \%$ (3 wt $\%$ of the catalyst) and carvone $15.4 \mathrm{~mol} \%$ (3 $\mathrm{wt} \%$ of the catalyst). Yield of 1,2-epoxylimonene was $1.5 \mathrm{~mol} \%$ for the catalyst content of $3 \mathrm{wt} \%$.

The most beneficial catalyst content for both studied catalysts was taken to be 3 wt $\%$.

The influence of the reaction time was investigated from 6 to $24 \mathrm{~h}$. The other reaction conditions were as follows: temperature $130{ }^{\circ} \mathrm{C}$ for Ti-MCM-41 catalyst and $140{ }^{\circ} \mathrm{C}$ for the Ti-MWW; molar ratio limonene:TBHP 1:1; amount of solvent Ti-MCM-41 $80 \mathrm{wt} \%$, Ti-MWW $70 \mathrm{wt} \%$; amount of catalyst $3 \mathrm{wt} \%$, and the intensity of stirring $500 \mathrm{rpm}$. The results are shown in Table 5.

During the studies on the influence of the reaction time on the course of limonene oxidation over the Ti-MCM-41 catalyst, the highest conversion of limonene to 1,2epoxylimonene, its diol, carveol, carvone and perillyl alcohol was obtained for the reaction time $6 \mathrm{~h}-94.7 \mathrm{~mol} \%$. Prolongation of the reaction time results in the following reactions, mainly polymerization reactions. The highest yield of perillyl alcohol was obtained for the reaction time of $6 \mathrm{~h}$ and amounted to $58.6 \mathrm{~mol} \%$. High values of the yield of carveol were obtained for the reaction time: 6 and $12 \mathrm{~h}$. After

Table 5 The influence of reaction time

\begin{tabular}{llccccc}
\hline Reaction time (h) & $\begin{array}{l}\mathrm{Y}_{\mathrm{EL}} \\
(\mathrm{mol} \%)\end{array}$ & $\begin{array}{l}\mathrm{Y}_{\mathrm{ELD}} \\
(\mathrm{mol} \%)\end{array}$ & $\begin{array}{l}\mathrm{Y}_{\mathrm{CN}} \\
(\mathrm{mol} \%)\end{array}$ & $\begin{array}{l}\mathrm{Y}_{\mathrm{CL}} \\
(\mathrm{mol} \%)\end{array}$ & $\begin{array}{l}\mathrm{Y}_{\mathrm{AP}} \\
(\mathrm{mol} \%)\end{array}$ & $\begin{array}{l}\mathrm{C}_{\mathrm{L}} \\
(\mathrm{mol} \%)\end{array}$ \\
\hline \multicolumn{2}{l}{ Studies with Ti-MCM-41 } & & & & & \\
6 & 1.5 & 6.2 & 0.5 & 28.0 & 58.6 & 94.7 \\
12 & 2.8 & 25.4 & 1.1 & 31.6 & 11.4 & 72.3 \\
24 & 2.5 & 59.5 & 14.3 & 0.3 & 6.6 & 83.2 \\
Studies with Ti-MWW & & & & & & 59.1 \\
6 & 0.0 & 5.0 & 0.0 & 14.2 & 39.2 \\
12 & 7.1 & 5.6 & 1.0 & 9.0 & 18.4 & 41.1 \\
24 & 0.2 & 3.6 & 0.0 & 8.7 & 14.2 & 26.7 \\
\hline
\end{tabular}


$24 \mathrm{~h}$ of reaction performing, a high yield of 1,2-epoxylimonene diol was reached$59.5 \mathrm{~mol} \%$.

During the studies over the Ti-MWW catalyst, the highest conversion of limonene was achieved for the reaction time of $6 \mathrm{~h}-58.2 \mathrm{~mol} \%$. The highest values of yields of perillyl alcohol and carveol were obtained for the reaction time $6 \mathrm{~h}-$ 39.1 and 14.2, respectively.

At this stage of studies, the most favorable was taken the reaction time of $6 \mathrm{~h}$. During the tests, it was observed that the prolongation of the reaction time caused the occurrence of subsequent reactions, mainly polymerization reactions, which was manifested by the darkening of the reaction solutions (dark brown). Polymer products were not determined.

\section{Conclusions}

During the studies performed over Ti-MCM-41 catalyst the following parameters were taken as the most beneficial: temperature $130{ }^{\circ} \mathrm{C}$, molar ratio limonene : TBHP 1:1; amount of solvent $80 \mathrm{wt} \%$, amount of the catalyst $3 \mathrm{wt} \%$, and reaction time $6 \mathrm{~h}$ (at the intensity of stirring $500 \mathrm{rpm}$ ). Under these conditions, the conversion of limonene was $94.7 \mathrm{~mol} \%$, and yields of main products were as follows: perillyl alcohol $58.6 \mathrm{~mol} \%$, and carveol $28 \mathrm{~mol} \%$. During the studies over Ti-MWW catalyst, the following parameters were taken as the most beneficial: temperature $140{ }^{\circ} \mathrm{C}$, molar ratio limonene : TBHP 1:1; amount of solvent $70 \mathrm{wt} \%$, amount of the catalyst $3 \mathrm{wt} \%$, and the reaction time $6 \mathrm{~h}$ (at the intensity of stirring $500 \mathrm{rpm}$ ). Under these conditions, the conversion of limonene was $59.2 \mathrm{~mol} \%$, and yields of main products were as follows: perillyl alcohol $39.1 \mathrm{~mol} \%$, and carveol $14.2 \mathrm{~mol} \%$.

The most beneficial conditions for both studied catalysts are very close but the values of main functions describing the process are different. Over the Ti-MCM-41 catalyst, it is possible to obtain almost twice as much conversion of limonene as over the Ti-MWW catalyst. This difference may result from the differences in the content of titanium, which is the active center of the catalyst: Ti-MCM-41-1.33 $\mathrm{wt} \%$, and Ti-MWW $1.0 \mathrm{wt} \%$. In addition, over the Ti-MCM-41 catalyst during the studies on the effect of the molar ratio of limonene/TBHP molar, the possibility of limonene autoxidation by oxygen from the air, in which the $-\mathrm{OH}$ groups present on the surface of the Ti-MCM-41 catalyst took part, was observed. This phenomenon was not as clearly visible in the case of the oxidation of limonene over the Ti-MWW catalyst.

Certainly, the reactivity of both catalysts is also influenced by the pore size and thus the availability of active titanium centers. It seems that in the case of Ti-MWW, limonene molecules have difficult access to these centers, as evidenced by the low conversion of limonene compared to Ti-MCM-41. Also, the -OH groups present on the surface of the Ti-MWW catalyst do not play such a significant role in the oxidation process as in the case of Ti-MCM-41 catalyst.

In our previous work [18], we described limonene epoxidation, inter alia, TiMCM-41 and Ti-MWW catalysts. The tests were carried out in reactors of larger 
volume (glass rector with a capacity of $100 \mathrm{~cm}^{3}$ - under atmospheric pressure and in an autoclave with a Teflon insert with a capacity of $150 \mathrm{~cm}^{3}$ - under autogenic pressure). A comparison of the results obtained in these studies is difficult due to the change in the volume of reactors, which has a significant impact on the course of the limonene oxidation process. In addition, these catalysts also had a different content of titanium Ti-MCM-41 $1.5 \mathrm{wt} \%$, and Ti-MWW $3.22 \mathrm{wt} \%$. Especially in the latter case, the obtained results could have been influenced by the presence of anatase, which at such high titanium contents usually accumulates in the pores of the catalyst. In the studies presented in the literature [18], Ti-MWW catalyst yielded significantly lower conversions of limonene- $17 \mathrm{~mol} \%$ in comparison to Ti-MCM41 catalyst $-94 \mathrm{~mol} \%$ (tests were conducted at $140{ }^{\circ} \mathrm{C}$, at the equimolecular ratio of reactants, at the methanol concentration of $80 \mathrm{wt} \%$, at the catalyst content $3 \mathrm{wt} \%$ and for the reaction time $3 \mathrm{~h}$ ).

Extending the reaction time to $6 \mathrm{~h}$ (results presented in the present work) did not result in the increase in the conversion of limonene on the Ti-MCM-41 catalyst, while the conversion of limonene on the Ti-MMM catalyst increased up to $58.2 \mathrm{~mol} \%$. This may indicate a worse availability of active sites in the Ti-MWW catalyst tested in our earlier work.

The studies of other researchers (showed in the Introduction part) presented that the epoxidation of limonene caused formation mainly of 1,2-epoxylimonene or mixture of 1,2- and 8,9-epoxylonene (or diepoxide). We showed that it is possible formation of perillyl alcohol and carveol in reaction limonene with TBHP over TiMCM-41 and Ti-MWW catalysts and it is novelty of our studies.

Open Access This article is distributed under the terms of the Creative Commons Attribution 4.0 International License (http://creativecommons.org/licenses/by/4.0/), which permits unrestricted use, distribution, and reproduction in any medium, provided you give appropriate credit to the original author(s) and the source, provide a link to the Creative Commons license, and indicate if changes were made.

\section{References}

1. Breck DW (1974) Zeolite molecular sieves, structure, chemistry and use. Wiley, New York

2. Bevilacqua M, Montanari T, Finocchio E, Busca G (2006) Are the active sites of protonic zeolites generated by the cavities? Catal Today 116(2):132-142

3. Jansen AH, Koster AJ, de Jong KP (2001) Three- dimensional transmission electron microscopic observations of mesoporous in dealuminated zeolite Y. Angew Chem Int Ed 40(6):1102-1104

4. Wróblewska A, Fajdek A, Milchert E, Grzmil B (2010) The Ti-MWW catalyst-its characteristic and catalytic properties in epoxidation of allyl alcohol by hydrogen peroxide. Pol $\mathrm{J}$ Chem Technol 12:29-34

5. Kim TK, Yang ST, Park RD, Song IK, Jung KE, Ahn WS (2010) Ti-MWW synthesis and catalytic application in partial oxidation reactions. Top Catal 53:470

6. Kresege CT, Leonowcz ME, Roth WJ, Vartuli JC, Beck SB (1992) Ordered mesoporous molecular sieves synthesized by a liquid-crystal template mechanism. Nature 359:710

7. Ziołek M (2004) Catalytic liquid-phase oxidation in heterogenous system as a green chemistry goal-advantages and disadventages of MCM-41 used as catalyst. Catal Today 90:145-150

8. Galacho C, Ribeiro Carrott MML, Carrott PJM (2007) Structural and catalytic properties of TiMCM-41 synthesied at room temperature up to high Ti-content. Micropor Mesopor Mater 100:312-321

9. Wróblewska A, Fajdek A, Wajzberg J, Milchert E (2009) Epoxidation of allyl alcohol over mesoporous Ti-MCM-41 catalyst. J Hazard Mater 170:405-410 
10. Tanev PT, Chibwe T, Pinnavaia JP (1994) Titanium-containing mesoporous molecular sieves for catalytic oxidation of aromatic compounds. Nature 368:321

11. Corma A, Navarro MT, Pariente JP (1994) Synthesis of an ultralarge pore titanium silicate isomrphous to MCM-41 and its application as a catalyst for selective oxidation of hydrocarbons. J Chem Soc Chem Commun 2:147-148

12. Rios LA, Weckes P, Schuster H, Hoelderich WH (2005) Mesoporous and amorphous Ti-silicas on the epoxidation of vegetable oils. J Catal 232:19

13. Corma A, Iglesias M, Sanchez H (1996) Large pore Ti-zeolite and mesoporous Ti-silicates as catalysts for selective oxidation of organic sulfides. Catal Lett 39:153

14. Berlini C, Guidotti M, Moretti G, Psaro R, Ravisio N (2000) Catalytic epoxidation of unsaturated alcohols on Ti-MCM-41. Catal Today 60:219

15. Estevez Y, Gardart C, Berthelot K, Grau E, De Jeso B, Quardad S, Peruch F (2014) Unexpected dimerization of isoprene in a gas chromatography inlet. A study by gas chromatography/mass spectrometry coupling. J Chromatogr A 1331:133

16. Launay F, Jarry B, Bonardet JL (2009) Catalytic activity of mesoporous Ga-SBA-15 materials in $\alpha$ pinene isomerization: similarities and differences with Al-SBA-15 analogues. Appl Catal A 368(1-2):132-138

17. Sharama S, Srivastawa AK (2005) Free radical copolimerization of limonene with buthyl methacrylane. Synthesis and characterization. Indian J Technol 12:62-67

18. Wróblewska A, Makuch E, Miądlicki P (2015) The oxidation of limonene at raised pressure and over the various titanium-silicate catalyst. Pol J Chem Technol 17(4):82

19. Almeida AAA, Costa JP, Carvalho RBF, Sousa DP, Feritas RM (2012) Evaluation of acute toxicity of a natural compound (+)-limonene epoxide and its anxiolytic-like action. Brain Res 1448:56

20. Fraile JM, Garcia JI, Mayoral JA, Menorval LC, Rachdi F (1995) A new titanium-silica catalyst for the epoxidation of non-functionalized alkenes and allylic alcohols, J. Soc Chem Commun, Chem, p 539

21. Herrero E, Casuscelli S, Fernandez J, Poncio C, Rueda C, Oyola O (2000) Catalystic epoxidation of limonene. Molecules 5:336

22. Guidotti M, Ravasio N, Psaro R, Ferraris G, Moretti G (2003) Epoxidation on titaniu-containing silicates: do structural features really affect the catalytic performance? J Catal 214:242

23. Wu P, Nuntasri D, Ruan J, Liu Y, He M, Fan W, Terasaki O, Tatsumi T (2004) Delamination of TiMWW and high efficiency in epoxidation of alkenes with various molecular sizes. J Phys Chem 108:19126

24. Guidotti M, Batonneau-Gener I, Gianotti E, Marchese L, Mignard S, Psaro R, Sgobba M, Ravasio N (2008) The effect of silylation on titanium-containing silica catalysts for epoxidation of functionalized molecules. Micropor Mesopr Mater 111:39

25. Guidotti M, Psaro R, Batonneau-Gerner I, Gavrilova E (2011) Heterogeneous catalytic epoxidation: high limonene oxide yields by surface silylation of Ti-MCM-41. Chem Eng Technol 34(11):1924

26. Gallo A, Tiozzo C, Psaro R, Carniato F, Guidotti M (2013) Niobium metallocenes deposited onto mesoporous silica via dry impregnation as catalysts for selective epoxidation of alkenes. J Catal 298:77

27. Kholdeeva A (2014) Recent developments in liquid-phase selective oxidation using environmentally bening oxidants and mesoporous metal silicates 4:1869

28. Charbonneau L, Kaliaguine S (2017) Epoxidation of limonene over low coordination Ti in Ti-SBA16. Appl Catal A 533:1

29. Cagnoli MV, Casucelli SG, Alvarez AM, Bengoa JF, Gallegos NG, Sammaniego NM, Crivello ME, Ghione GE, Perez CF, Herrero ER, Marchetti SG (2005) "Clean” limonene epoxidation usig TiMCM-41 catalyst. Appl Catal A 287:227-235

30. Bonon AJ, Kozlov YN, Bahu JO, Filho RM, Mandelli D, Shul'pin GB (2014) Limonene epoxidation with $\mathrm{H}_{2} \mathrm{O}_{2}$ promoted by $\mathrm{Al}_{2} \mathrm{O}_{3}$ : kinetic study, experimental design. J Catal 319:71-86

31. Wróblewska A (2014) The epoxidation of limonene over the TS-1 and Ti-SBA-15 catalysts. Molecules 19:19907-19922

32. Wróblewska A, Makuch E, Miądlicki P (2016) The studies on the limonene oxidation over the microporous TS-1 catalyst. Catal Today 268:121-129

33. Wu P, Tatsumi T, Komatsu T, Yashima T (2001) A novel titanosilicate with MWW structure. I. Hydrothermal synthesis, elimination of extraframework titanium, and characterizations. J Phys Chem B 105(15):2897-2905. https://doi.org/10.1021/jp002816s 
34. Yue C, Xie W, Liu Y, Wu H, Li X, Wu P (2011) Hydrothermal synthesies of MWW-type analogues using linear-type quaternary alkylammonium hydroxides as structure-directing agents. Micropr Mesopr Mater 142:347

35. Corma A, Camblor M, Esteve PA, Martinez M, Perez-Pariente J (1994) Activity of Ti-Beta catalyst for the selective oxidation of alkenes and alkanes. J Catal 145:151-158

36. Bellussi G, Rigguto MS (2001) Chapter 19 metal ions associated to molecular sieve frameworks as catalytic sites for selective oxidation reactions. Stud Surf Sci Catal 137:911

37. Balducci L, Bianchi D, Bortolo R, D’Alosio R, Ricci M, Tassinari R, Ungarelli R (2003) Direct Oxidation of benzene to phenol with hydrogen peroxide over modified titanium silicate. Angew Chem Int Ed 42:4937

38. Wu P, Xu H, Xu L, Liu Y, He M (2013) MWW-type Titanosilicate, synthesis, structural modification and catalytic applications to green oxidations. Springer, New York. https://doi.org/10.1007/978-3642-39115-6_2

39. Zhou D, Zhang H, Zhang J, Sun X, Li H, He N, Zhang W (2014) Denisty functional theory investigation into the structure and spectroscopic properties of the $\mathrm{Ti}^{4+}$ species in Ti-MWW zeolite. Micropor Mesopor Mater 195:216-226

40. Vayssilov GN (1997) Structural and physiocochemical features of titanium silicates. Catal Rev Sci Eng 39:209

41. Soult AS, Poore DD, Mayo EI, Stiegman AE (2001) Electronic spectroscopy of the titanium centers in titanium silicates. J Phys Chem B 105(14):2687

42. Camblor MA, Corma A, Pérez-Pariente J (1993) Infrared spectroscopic investigation of titanium zeolites. A new assignment of the $960 \mathrm{~cm}^{-1}$ band. J Chem Soc Chem Commun 6:557

43. Shumacher K, Grün M, Unger K (1999) Novel synthesis of spherical MCM-48. Micropor Mesopor Mater 27:201-206

44. Wróblewska A, Makuch E (2013) Studies on the deactivation of Ti-MCM-41 catalyst in the process of allyl alcohol epoxidation. Pol J Chem Technol 15:111-115 